\title{
Increasing Environmental Protection Investment is an Important Measure to Prompt Enterprises to Reduce Pollutants Emission
}

\author{
Chuanlian Song \\ College of Economics \& Management \\ Changchun University of Science and Technology, Changchun 130022, China \\ E-mail: chuanliansong@163.com
}

Received: March 4, 2011

Accepted: March 14, 2011

doi:10.5539/ijef.v3n4p245

\begin{abstract}
The article discusses current "environmental impact assessment system" and "three simultaneous" system in China. In the opinion of author, current systems cannot prompt enterprises to reduce pollutants emission fundamentally, and thus put forward controlling corporate pollution reduction should not hinder economic development, and keeping economic sustainable increase is the premise of promoting pollution reduction in enterprises. Through empirical analysis of pollution investment data in 31 provinces, autonomous regions and municipalities of China, the author finds that $60 \%-100 \%$ of environmental investment in each district is from non-governmental investment, which is not conductive to prompt enterprises to reduce pollutants emission or economic sustainable development. To keep economic sustainable development, environmental investment must be increased. Because of the public characteristic of environmental cost, increasing environmental protection investment is an important measure to prompt enterprises to reduce pollutants emission.
\end{abstract}

Keywords: environmental impact assessment system, Three simultaneous, Environmental investment in China's enterprise, Investment analysis, Sustainable development

\section{Introduction}

Reducing pollutants emission in enterprises cannot be an armchair strategist or an empty slogan, but should take practical measures. The control and treatment of pollutants emission in enterprises need the effects of enterprises and social supervision, as well as the role of the government. Through investigation it is found that enterprises control and deal with pollution passively, the reason for which is that it's difficult to finance environmental investment. The nature of enterprises driven by profit decides they need material rewards and investment from the government when controlling pollution. But the public usually just care for the environmental problems which have large influence on them, together with their dispersion in reality, and the existence of the problems such as the motivation that they need social recognition, make the public cannot better supervise corporate environmental problems. To motivate the public to form the supervision forces for pollution and arouse their enthusiasm also needs corresponding incentive measures. Therefore, increasing environmental investment is an important way to promote pollutants emission reduction in all levels of government currently.

\section{The evaluation for current "environmental impact assessment system" and "three simultaneous" system in China}

In order to control the pollution of a project that may happen, current systems in China are mainly "environmental impact assessment system" and "three simultaneous" system.

"Environmental impact assessment system" refers to a legal system that a region carries out construction projects that may affect the environment, prior to its activities the government or related departments carry out the potential environmental impact survey, forecasting and evaluation, and countermeasures for prevention of environmental pollution and destruction are proposed and appropriate solutions are formulated.

Generally, through project environmental impact assessment system, it can provide basis for reasonable location of construction projects and prevent difficultly eliminate damage brought by unreasonable layout; through project environmental impact assessment system, it can investigate the situations of surrounding environment, predict the scope, degree and tendency that construction projects influence environment and propose targeted environmental protection measures; environmental impact assessment system also provide scientific basis for the environmental management of construction projects. Environmental impact assessment system is seen as a predictive environmental policy and causes more and more concerns internationally. But the viewpoint in the article is that, 
excessively strict implementation of environmental impact assessment system inevitably avoids more environmental problems, but too strict limits will influences economic development.

"Three simultaneous" system refers to the measures of preventing and controlling pollution in construction projects, which must designed, constructed and put into operation simultaneously with the principal part of the project. The measures of preventing and controlling pollution must be inspected and passed by environmental authorities that examine and approve original environmental impact report originally, and then the construction project is put into operation or use.

"Three simultaneous" system applies to new, reconstruction and expansion projects (including small-scale construction project) and technological transformation projects, as well as other construction projects and natural development projects which are possible to cause pollution and damage to environment in China, which are supplementary and complementary with environmental impact assessment system, are two talismans to prevent new pollution and damage and belong to preventive cost control system.

Any project through confirmation of environmental impact assessment system that can develop and construct, when constructing, must follow the stimulation of "three simultaneous" system, implement environmental protection measures, and prevent producing new environmental problems after construction projects are put into use. In the process of projects construction, environmental pollution and ecological destruction should also be prevented. The key to implement environmental protection measures in the main chains in construction projects such as design, construction, and completion and acceptance, is to ensure that the investment, equipments and materials of environmental protection and the principal part of the project are arranged simultaneously so as to the requirements of environmental protection are implemented in every stage of infrastructure procedures. "Three simultaneous" system defines the duties of construction units, administrative departments and environmental protection department respectively, conductive to specific management, and supervision and law enforcement.

In conclusion, the article has evaluation on environmental impact assessment as follows:

Firstly, "environmental impact assessment system" and "three simultaneous" system are conductive to the control of high-pollution projects, which plays a role in limiting the pollution may brought by new, reconstruction and expansion projects which have tremendous influence on environment.

Secondly, the control of pollution through the two systems is mainly for whether projects will be new, rebuilt or expand, but has weak effects on the pollution control after projected is finished. In terms of time, the two systems cannot maintain the consistency of pollution controlling effects.

Thirdly, "environmental impact assessment system" and "three simultaneous" system raise the threshold of an industry. When preventing pollution, they also influence the initiative of investors to invest.

Fourthly, "three simultaneous" system accounts for a great deal of fund in enterprises, not conductive to subsequent technological reformation and development in enterprises.

\section{Controlling pollution should take economic increase as premise}

If a nation wants to become prosperous, and a country, a district wants to develop, it's necessary to develop productivity. Falling behind would be beaten is a truth that every Chinese should remember. Through analysis above, the authors think, in the process of the implementation of "environmental impact assessment system" and "three simultaneous" system, overemphasis on the investment of enterprises will influences investment initiative and corporate fund allocation and long-term development. From current development stage of China it can be seen, insufficient investment from place to place is still an outstanding contradiction of economic development. The viewpoint of the article is that controlling pollution should not hinder economic development.

How to deal with the contradiction between economic benefit and social benefit is the key to the problem. Because environmental benefit is a kind of public benefit, theoretically, the society should take more responsibilities for the protection and improvement of this kind of benefit. Because of the nature of enterprises driven by profit and the dispersion of the public, the initiative that enterprises and the public control pollution largely relies on the incentive, protection and maintenance of the government. Particularly in China or a developing country, it has not reached the degree that the public and enterprises firstly consider their own interests after social benefit. From the investment of purchase in market it can be seen, more customers buy cheap goods, while few people consider the pollution behind the goods and whether the production enterprises fulfill their social responsibilities.

To keep economic increase and control pollution, as well as sustain economic development, the government should solve corporate real difficulties. For example, increase the investment in environmental protection, do well in the construction of environmental infrastructure, build industrial parks, implement more incentives in the enterprises 
which control pollution positively, solve the problem of environmental cost in the operation of corporate pollution equipment. In order to strengthen supervision, the government should also bring the power of the public supervision into play, which needs the investment of the government.

\section{Analysis on the financial source of current pollution investment projects in China}

Now that increasing investment in environmental protection is able to keep economic sustainable development, how much of the financial source of current pollution investment projects is from the government in China? Through analysis of China Statistical Yearbook in 2006, 2007 and 2008 in the article it can be found that the fund of current pollution investment projects depend more on self-funding, specific to see table 1 , table 2 , table 3 , table 4 , table 5 .

Through empirical analysis above it can be found that, the number of the provinces whose proportion of non-governmental investment in environmental protection in 2005 and 2006 is over $90 \%$ is 19 and 22 respectively, and both numbers whose proportion is over $80 \%$ is are 28 , specific to see table 5 . Therefore, that it's difficult to finance environmental protection is the main reason for enterprises to control pollution passively currently.

\section{Conclusions}

Enterprises and individuals are both customers and users of environmental resource, and destroyers of them. Increasing investment in environmental protection will cut their profitable space while the public are not willing to pay for corporate environmental cost. This shows the government should play their role in managing and controlling public resources, among which the foremost way is to increase investment in environmental protection.

Through analysis above the article suggests that Chinese government should increase investment in environmental protection in order to maintain economic sustainable growth. Otherwise, what's called pollution control is just an empty slogan.

\section{References}

Chen, Sugen. (2007). American processing industry of agricultural products who attach importance to. NEWSLETTER ABOUT WORK IN RURAL AREAS. 2007, No. 6.

China Statistical Yearbook in 2006, 2007 and 2008. China Statistics Publishing House.

Li, Jiyu. (2007). Consideration on strengthening the overall control to promote pollution reduction. Energy conservation and pollution reduction. 2007, No. 12.

Ning, Jing. (2007). Current situations about Green GDP accounting in China. Co-operative economy and science. 2007, No. 4 .

Song, Chuanlian. (2009). Analysis on reasons for the out of control of the environmental cost of agricultural products processing industry in Jilin Province. Productivity research. No. 11.

$\mathrm{Xu}$, Xiangming \& Yu, Ming. (2005). The adjustment and control mechanism in water pollution control legislation in USA. Environmental Protection. 2005, No. 12. 
Table 1. The financial source and their proportion of current pollution investment projects in 31 provinces, autonomous regions and municipalities of China in 2005

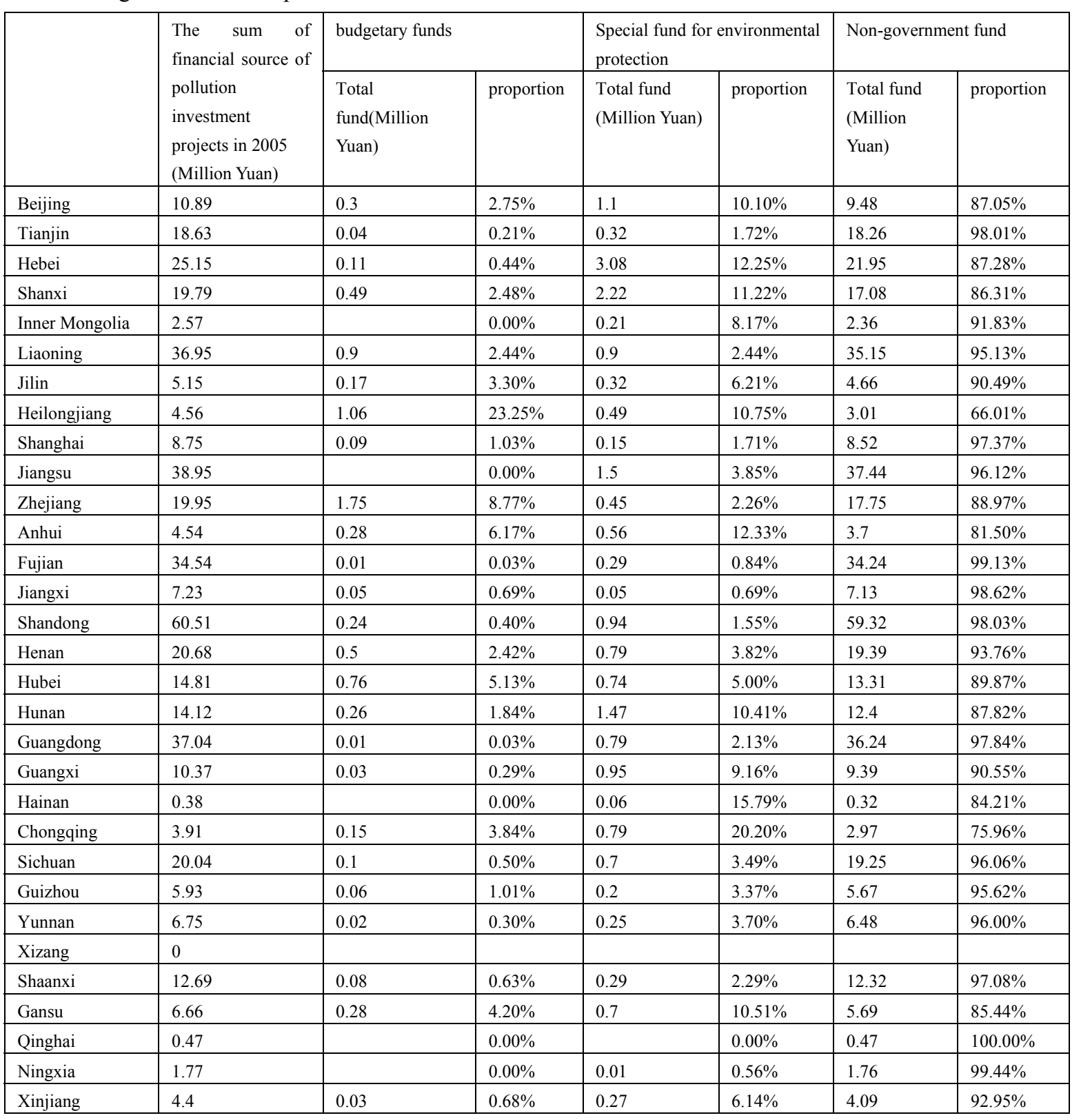

Table 2. The proportion of non-governmental investment in environmental protection in total pollution investment in 30 provinces, autonomous regions and municipalities of China except Xizang in 2005

\begin{tabular}{|c|c|c|c|c|c|c|c|c|c|c|}
\hline Qinghai & Ningxia & Fujian & Jiangxi & Shandong & Tianjin & \multicolumn{2}{|c|}{ Guangdong } & Shanghai & Shaanxi & Jiangsu \\
\hline $100.00 \%$ & $99: 44 \%$ & $99.13 \%$ & $98.62 \%$ & $98.03 \%$ & $98.01 \%$ & \multicolumn{2}{|c|}{$97.84 \%$} & $9737 \%$ & $97.08 \%$ & $96.12 \%$ \\
\hline \multicolumn{11}{|c|}{ Continue } \\
\hline Sichuan & Yunnan & Guizhou & Liaoning & Henan & \multicolumn{2}{|c|}{ Xinjiang } & $\begin{array}{l}\text { Inner } \\
\text { Mongolia } \\
\end{array}$ & Guangxi & Jilin & Hubei \\
\hline $96.06 \%$ & $96.00 \%$ & $95.62 \%$ & $95.13 \%$ & $93.76 \%$ & $9295 \%$ & & $1.83 \%$ & $9055 \%$ & $90.49 \%$ & $89.87 \%$ \\
\hline \multicolumn{11}{|c|}{ Continue } \\
\hline Zhejiang & Hunan & Hebei & Beijing & Shanxi & Gansu & \multirow{2}{*}{$\begin{array}{l}\text { Henan } \\
8421 \%\end{array}$} & Anhui & Chongqin & \multicolumn{2}{|c|}{ Heilongjiang } \\
\hline $88.97 \%$ & $87.82 \%$ & $8728 \%$ & $87.05 \%$ & $8631 \%$ & $85.44 \%$ & & $8150 \%$ & $75.96 \%$ & \multicolumn{2}{|c|}{$66.01 \%$} \\
\hline
\end{tabular}


Table 3. The financial source and their proportion of current pollution investment projects in 31 provinces, autonomous regions and municipalities of China in 2006

\begin{tabular}{|c|c|c|c|c|c|c|c|}
\hline & \multirow{2}{*}{$\begin{array}{l}\text { The sum of } \\
\text { financial source of } \\
\text { pollution } \\
\text { investment } \\
\text { projects in } 2006 \\
\text { (Million Yuan) }\end{array}$} & \multicolumn{2}{|c|}{ Pollution fee subsidy } & \multicolumn{2}{|c|}{$\begin{array}{l}\text { Other subsidies from } \\
\text { government }\end{array}$} & \multicolumn{2}{|l|}{ Non-government fund } \\
\hline & & $\begin{array}{l}\text { Total } \\
\text { fund } \\
\text { (Million } \\
\text { Yuan) }\end{array}$ & proportion & $\begin{array}{l}\text { Total fund } \\
\text { (Million } \\
\text { Yuan) }\end{array}$ & proportion & $\begin{array}{l}\text { Total fund(Million } \\
\text { Yuan) }\end{array}$ & $\begin{array}{l}\text { proportio } \\
\mathrm{n}\end{array}$ \\
\hline Beijing & 10.13 & 0.3 & $2.96 \%$ & 2.04 & $20.14 \%$ & 7.81 & $77.10 \%$ \\
\hline Tianjin & 14.95 & 0.16 & $1.07 \%$ & 0.48 & $3.21 \%$ & 14.31 & $95.72 \%$ \\
\hline Hebei & 19.09 & 1.04 & $5.45 \%$ & 0.82 & $4.30 \%$ & 17.21 & $90.15 \%$ \\
\hline Shanxi & 36.76 & 3.05 & $8.30 \%$ & 0.95 & $2.58 \%$ & 32.75 & $89.09 \%$ \\
\hline $\begin{array}{l}\text { Inner } \\
\text { Mongolia }\end{array}$ & 17.72 & 0.27 & $1.52 \%$ & 0.03 & $0.17 \%$ & 17.42 & $98.31 \%$ \\
\hline Liaoning & 52.05 & 0.65 & $1.25 \%$ & 1.13 & $2.17 \%$ & 50.28 & $96.60 \%$ \\
\hline Jilin & 3.98 & 0.017 & $0.43 \%$ & 0.06 & $1.51 \%$ & 3.9 & $97.99 \%$ \\
\hline Heilongjiang & 5.82 & 0.054 & $0.93 \%$ & 0.1 & $1.72 \%$ & 5.67 & $97.42 \%$ \\
\hline Shanghai & 5.93 & 0 & $0.00 \%$ & 0.01 & $0.17 \%$ & 5.91 & $99.66 \%$ \\
\hline Jiangsu & 28.01 & 0.98 & $3.50 \%$ & 0.24 & $0.86 \%$ & 26.79 & $95.64 \%$ \\
\hline Zhejiang & 25.04 & 0.53 & $2.12 \%$ & 0.01 & $0.04 \%$ & 24.43 & $97.56 \%$ \\
\hline Anhui & 5.46 & 0.28 & $5.13 \%$ & 0.39 & $7.14 \%$ & 4.79 & $87.73 \%$ \\
\hline Fujian & 19.6 & 0.2 & $1.02 \%$ & 0.15 & $0.77 \%$ & 19.26 & $98.27 \%$ \\
\hline Jiangxi & 6.86 & 0.28 & $4.08 \%$ & 0.05 & $0.73 \%$ & 6.53 & $95.19 \%$ \\
\hline Shangdong & 59.66 & 0.77 & $1.29 \%$ & 1.13 & $1.89 \%$ & 57.76 & $96.82 \%$ \\
\hline Henan & 24.73 & 0.51 & $2.06 \%$ & 1.23 & $4.97 \%$ & 22.99 & $92.96 \%$ \\
\hline Hubei & 14.89 & 0.29 & $1.95 \%$ & 0.9 & $6.04 \%$ & 13.69 & $91.94 \%$ \\
\hline Hunan & 17.33 & 0.87 & $5.02 \%$ & 1.17 & $6.75 \%$ & 15.29 & $88.23 \%$ \\
\hline Guangdong & 31.37 & 0.21 & $0.67 \%$ & 1.04 & $3.32 \%$ & 30.11 & $95.98 \%$ \\
\hline Guangxi & 8.66 & 0.33 & $3.81 \%$ & 0.05 & $0.58 \%$ & 8.29 & $95.73 \%$ \\
\hline Hainan & 2.14 & 0.01 & $0.47 \%$ & 0 & $0.00 \%$ & 2.13 & $99.53 \%$ \\
\hline Chongqing & 3.67 & 0.15 & $4.09 \%$ & 0.43 & $11.72 \%$ & 3.1 & $84.47 \%$ \\
\hline Sichuan & 20.3 & 0.79 & $3.89 \%$ & 0.55 & $2.71 \%$ & 18.96 & $93.40 \%$ \\
\hline Guizhou & 10.08 & 1.73 & $17.16 \%$ & 0.04 & $0.40 \%$ & 8.31 & $82.44 \%$ \\
\hline Yunnan & 9.41 & 0.14 & $1.49 \%$ & 0.19 & $2.02 \%$ & 9.09 & $96.60 \%$ \\
\hline Xizang & 0.01 & & $0.00 \%$ & 0.01 & $100.00 \%$ & 0 & $0.00 \%$ \\
\hline Shaanxi & 7.37 & 0.15 & $2.04 \%$ & 0.07 & $0.95 \%$ & 7.15 & $97.01 \%$ \\
\hline Gansu & 13.65 & 0.39 & $2.86 \%$ & 1.89 & $13.85 \%$ & 11.37 & $83.30 \%$ \\
\hline Qinghai & 0.78 & 0 & $0.00 \%$ & 0.13 & $16.67 \%$ & 0.65 & $83.33 \%$ \\
\hline Ningxia & 3.99 & 0.05 & $1.25 \%$ & 0.01 & $0.25 \%$ & 3.93 & $98.50 \%$ \\
\hline Xinjiang & 4.52 & 0.08 & $1.77 \%$ & 0.13 & $2.88 \%$ & 4.31 & $95.35 \%$ \\
\hline
\end{tabular}

Table 4. The proportion of non-governmental investment in environmental protection in total pollution investment in 30 provinces, autonomous regions and municipalities of China except Xizang in 2006

\begin{tabular}{|c|c|c|c|c|c|c|c|c|c|c|c|}
\hline Shanghai & Hainan & Ningxia & $\begin{array}{l}\text { Inner } \\
\text { Mongolia }\end{array}$ & Fujian & Jilin & \multicolumn{2}{|c|}{ Zhejiang } & \multicolumn{2}{|c|}{ Heilongjiang } & Shaanxi & Shandong \\
\hline $99.66 \%$ & $9953 \%$ & $98.50 \%$ & $9831 \%$ & $9827 \%$ & $9799 \%$ & \multicolumn{2}{|c|}{$97.56 \%$} & \multicolumn{2}{|c|}{$97.42 \%$} & $97.01 \%$ & $96.82 \%$ \\
\hline \multicolumn{12}{|c|}{ continue } \\
\hline Liaoning & Yunnan & Guangdong & Guangxi & Tianjin & Jian & & Xin & ang & Jiangxi & Sichuan & Henan \\
\hline $96.60 \%$ & $96.60 \%$ & $95.98 \%$ & $95.73 \%$ & $95.72 \%$ & 95.64 & & 9535 & & $95.19 \%$ & $93.40 \%$ & $92.96 \%$ \\
\hline \multicolumn{12}{|c|}{ continue } \\
\hline Hubei & Hebei & Shanxi & Hunan & Anhui & $\begin{array}{l}\text { Chon } \\
\text { g }\end{array}$ & & Qing & & Guizhou & Beijing & $\begin{array}{l}\text { Heihongj } \\
\text { iang }\end{array}$ \\
\hline $91.94 \%$ & $90.15 \%$ & $89.09 \%$ & $88.23 \%$ & $87.73 \%$ & $84.47 \%$ & & $8333^{\circ}$ & & $82.44 \%$ & $77.10 \%$ & $66.01 \%$ \\
\hline
\end{tabular}


Table 5. The statistical table of the proportion of non-governmental investment in environmental protection in total pollution investment in 2005 and 2006

\begin{tabular}{|l|l|l|l|l|l|l|l|l|}
\hline & \multicolumn{2}{|c|}{$90 \%-100 \%$} & \multicolumn{2}{|c|}{$80 \%-90 \%$} & \multicolumn{2}{|c|}{$70 \%-80 \%$} & \multicolumn{2}{c|}{$60 \%-70 \%$} \\
\hline 2005 & 19 & $63.33 \%$ & 9 & $30 \%$ & 1 & $3.33 \%$ & 1 & $3.33 \%$ \\
\hline 2006 & 22 & $73.33 \%$ & 6 & $20 \%$ & 1 & $3.33 \%$ & 1 & $3.33 \%$ \\
\hline
\end{tabular}

$$
\begin{aligned}
& \text { "Environmental impact } \\
& \text { assessment system" and } \\
& \text { "three simultaneous" } \\
& \text { system in China }
\end{aligned}
$$

Time

Figure 1. Schematic diagram of the relationship between environmental impact assessment system and "Three simultaneous" system and the time for sewage charges of the project 